\title{
THE IMPACT OF COVID-19 ON SCIENTIFIC RESEARCH IN CHINA: A CASE STUDY OF STATE UNIVERSITY IN SOUTH CHINA
}

\author{
Xinru Zhao ${ }^{1}$, Pan Lin ${ }^{2 *}$ \\ ${ }^{1}$ Ms, Jinan University, China, lokizhaoxr@163.com \\ ${ }^{2}$ Assistant Prof. Ms., Jinan University, 149768127@qq.com \\ ${ }^{*}$ Corresponding Author
}

\begin{abstract}
The outbreak of the Corona Virus in 2019 brought significant impact on more than 200 counties since 2019. Due to the intensification of the pandemic, every industry is under turbulence including agriculture, industry, medicine, finance, etc. Among them, the advancement of scientific research based on universities and institutes has been greatly affected. Scientific research, especially the research of nature science, is highly replying on data and professional equipment. Once universities and institutes are locked down, researchers cannot push forward their work without the prerequisite data and equipment. Therefore, scientific research can only be stalled. Meanwhile, the cancellation or postponement of international travel and scientific conferences is another reason that stopped scientific research completely or by half. Nevertheless, the quantitative analysis of how universities and institutions are influenced is still not clear, which makes it challengeable for policymakers to response to the disease wisely. This paper aimed to quantify the influence of COVID-19 on research of universities or institutions in China and find out the solution with high pertinence and maneuverability. The author used scientific projects data of Jinan University from 2015 to 2019 as input data and employed the Gray Model to forecast the number of projects of 2020. By comparing the predicted number to the true situation, we found that although the true number of scientific projects of Jinan University in 2020 (293 items) was higher than that of 2019 (273 items), there was still a big gap between the expected number of 2020 (327 items) and the true number (293 items) according to our model. Moreover, the average annual growth rate of projects has dropped from $22 \%$ to $19 \%$. This indicated that the pandemic did not cause a regression of scientific research, but it did slow down its development. In view of this, it is necessary to explore how universities should take effective measures to evolve the management of research and thus reduce the negative impact of the pandemic. These measures included but not limited to: 1) establishing a more reasonable research management system which meets the demand of plague prevention in China; 2) deepening the all-round reform of the scientific research evaluation system; 3) promoting the digitalization of the management of research and related technological achievements.
\end{abstract}

Keywords: COVID-19, Scientific Research, Gray Model, Management Promotion.

\section{INTRODUCTION}

The COVID-19 pandemic that broke out in December 2019 has spread around the world in a short period of time. According to the statistics from Boao Forum for Asia in June, more than 5 million people have been diagnosed and more than 300,000 people have died by May, 2020. Although the pandemic is gradually under control, it is undeniable that the pandemic has already changed the system of policy, economy, culture and so on. The report The Impact of Covid-19 on Higher Education around the World written by Giorgio Marinoni, Hilligje van't Land, and Trine Jensen in May 2020 said that scientific research relied on universities 
and institutes around the world has been greatly affected by the pandemic, for example, universities in China, the United States, and Europe have all been required to close down temporarily. In this case, students and staff have no choice but to study or work at home. At the same time, in order to reduce the impact of personnel movement and gathering on the prevention and control of the pandemic, many countries have cancelled international academic conferences, which made researchers unable to conduct longdistance field research. And it was impossible for them to carry out cooperation with the government and enterprises regarding the integration of production, education and research (Zhang, 2020). What is more important is that many research work, especially natural science research, requires the use of professional equipment to test or complete experiments. Once the school is closed, it is clear that home-office cannot meet the needs for researchers to finish their scientific work. In addition, because the online management system has not been upgraded and widely used in time, the administrative approval process of research in universities is often inefficient due to the lack of face-to-face communication. All the reasons above have brought together the advancement of scientific research work into a quagmire and stagnating. Jinan University is a state university in China, and its scientific research work has been affected by the above reasons as well. This paper will take Jinan University as an example to study the impact of the pandemic on scientific research in China.

Though there is a lot of research on the COVID-19 impact on scientific research of universities or institutes, most of them are about qualitative analysis. The quantitative analysis of the impact is not clear and comprehensive enough, so the innovation of this paper is to use the appropriate mathematic model to quantitatively analyze the substantial impact on the scientific research of Jinan University during the pandemic.

In view of the escalation of the globalization of the pandemic and the normalization of prevention and control, it is necessary to explore how to response to the future under the current situation to help researchers with scientific research work. The measures that we could take can be classified into two levels. One is that the central government and province governments are supposed to figure out how to use its administrative power to assist universities and institutions with their scientific research. The other one is that every university should set its own policy for itself in line with the future development of the pandemic under the premise of complying with national policies. Since Jinan University has recruited many teachers and students from Hong Kong, Macao and Taiwan, it is evitable to talk about how the university could protect its staff and try its best to ensure the development of scientific research work at the same time.

\section{METHODOLOGY}

\subsection{Data}

This paper used Jinan University as a case study to see the specific impact of the pandemic on scientific research in state universities in China in 2020. The data used here was the scientific research projects number of Jinan University from 2015 to 2020. The data included social science projects from the National Social Science Fund of China and natural science projects from the National Natural Science Fund of China.

\subsection{Model for Prediction}

This paper used the Gray Model to analyze and predict data. The Gray Model theory was first proposed by Professor Julong Deng in 1982. After the development of decades, the Gray Model has been upgraded for several time and is used by scholars to make precise predictions of data which is of a very small sample size. This model can be applied to social science, such as economy in Analysis of Hainan Province Marine Economic Development Trends (Chen, Wu, Zhang, Jiang, 2020), demography in Different Regional Distribution of Technological Talents and Their Effects (Zhao, 2020), environmental study in Analysis and Model Forecast of Influencing Factors of Forest Coverage in Qingyuan (Gao, Zhang, 2020) and tourism in Prediction of Hong Kong-Zhuhai-Macao Bridge's Impact on Zhuhai's Tourism Industry and Countermeasure Study (Mo, Gao, Xu, 2020), etc. Also, the model is widely used in natural science, like engineering in Discussion on the Application of Gray System in Building Settlement Prediction (Wu, 2020), chemistry in Chemical Milling Thickness Prediction Based on Grey Markov Process (Sui, Sun, Lai, Qiu, 2020), study of wind and water in The Scale of China's Offshore Wind Power Development Based on Grey Prediction Model and Trend Research (Dou, Xie, 2020) and medicine in Application of Grey System Theory in Identification of Dominant Species of Infectious Diseases and Pandemic Prediction (Wang, Zuo, Hong, 2011), etc. At last, there are studies on applying this model to the impact of the pandemic on various industries as well, such as the impact on GDP in Research on the Impact of the COVID-19 on Chinese GDP (Zhu, Gu, 2020). But no research has been done yet to employ the model to check the effects of COVID-19 on research in universities. 
From the paper above, we can see the advantages of the Gray Model are:

1. It does not require a large amount of data to support the prediction, and the data does not need to follow a certain statistically distribution;

2. It can be used for short-term and mid-to-long-term prediction;

3. The prediction is pretty accurate.

Since we only have the data of Jinan University from 2015 to 2020, whose sample size is too small to be applied with those traditional prediction models, so it is suitable to use the Gray Model for predictive analysis.

\subsection{Processing of Data}

The first step is to input the social science and natural science projects numbers of Jinan University from 2015 to 2019 into the model and calculate with the statistical software R. Then we could obtain the prediction numbers of national social science and national natural science projects of 2020 , which means that, we set the hypothesis that if there was no such a black swan incident (COVID-19), how many projects Jinan University could have in 2020. The second step is to compare the predicted numbers of projects in 2020 obtained in the first step with the real numbers of projects of Jinan University in 2020.

\section{RESULTS}

\subsection{Social Science}

We input the 2015-2019 national social science fund projects data of Jinan University into our model GM (1, 1). The prediction results showed that if there was no COVID-19 pandemic in 2020 , then the national social science projects of Jinan University in 2020 should be 75 items, and the prediction accuracy was 0.991 . The prediction accuracy is high enough.

Table 1. Social Science Projects of Jinan University (2015-2020)

\begin{tabular}{|c|c|c|c|c|}
\hline \multicolumn{5}{|c|}{ Social Science Projects of Jinan University (2015-2020) } \\
\hline Year & Projects (real) & Projects (predicted) & \multicolumn{2}{|c|}{ Annual Growth Rate } \\
\hline 2015 & 31 & & Real & Predicted \\
\hline 2016 & 49 & & 0.58 & \\
\hline 2017 & 48 & & -0.02 & \\
\hline 2018 & 52 & & 0.08 & \\
\hline 2019 & 70 & & 0.35 & \\
\hline 2020 & 70 & & 0.00 & 0.07 \\
\hline $\begin{array}{c}\text { Average Annual } \\
\text { Growth Rate }\end{array}$ & & & 0.20 & 0.21 \\
\hline
\end{tabular}

According to the table above, the real number of the national social science projects of Jinan University in 2020 is 70 items, which was 5 less than the predicted result 75 items. Thus, the social science projects decreased by $7.14 \%$. Based on our forecast, the annual growth rate in 2020 should be $7 \%$, but the real growth rate was 0 , and the annual growth rate has dropped by 7 percentage points. The real and predicted average annual growth rates from 2015 to 2020 are $20 \%$ and $21 \%$, respectively. 


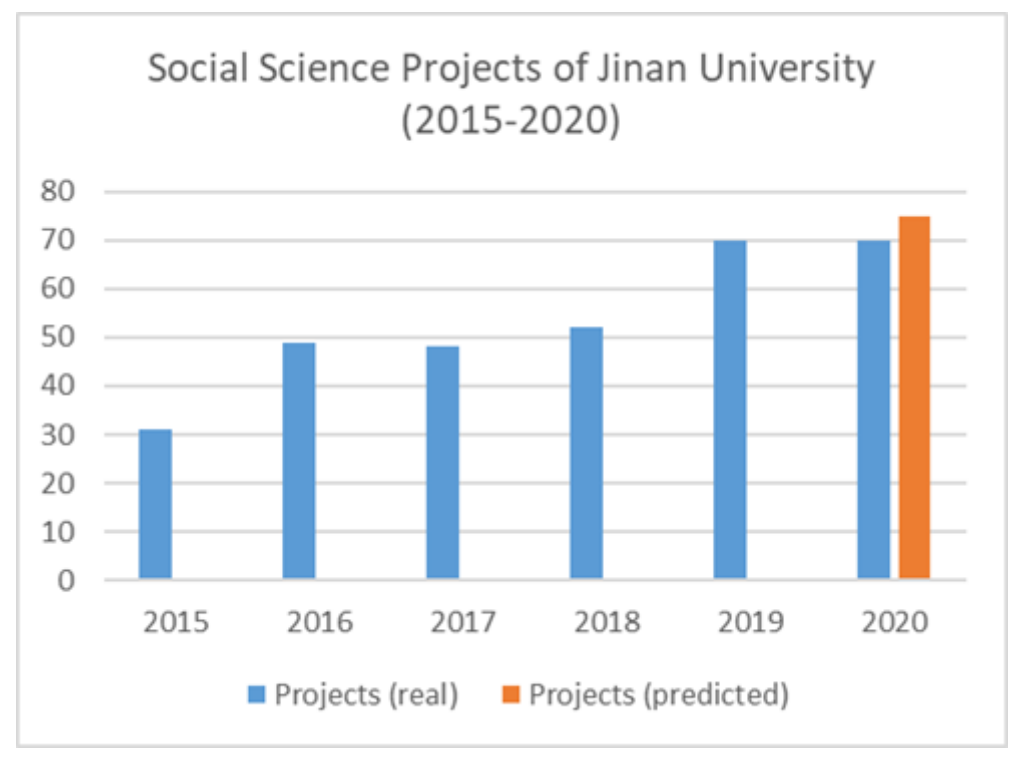

Fig. 1

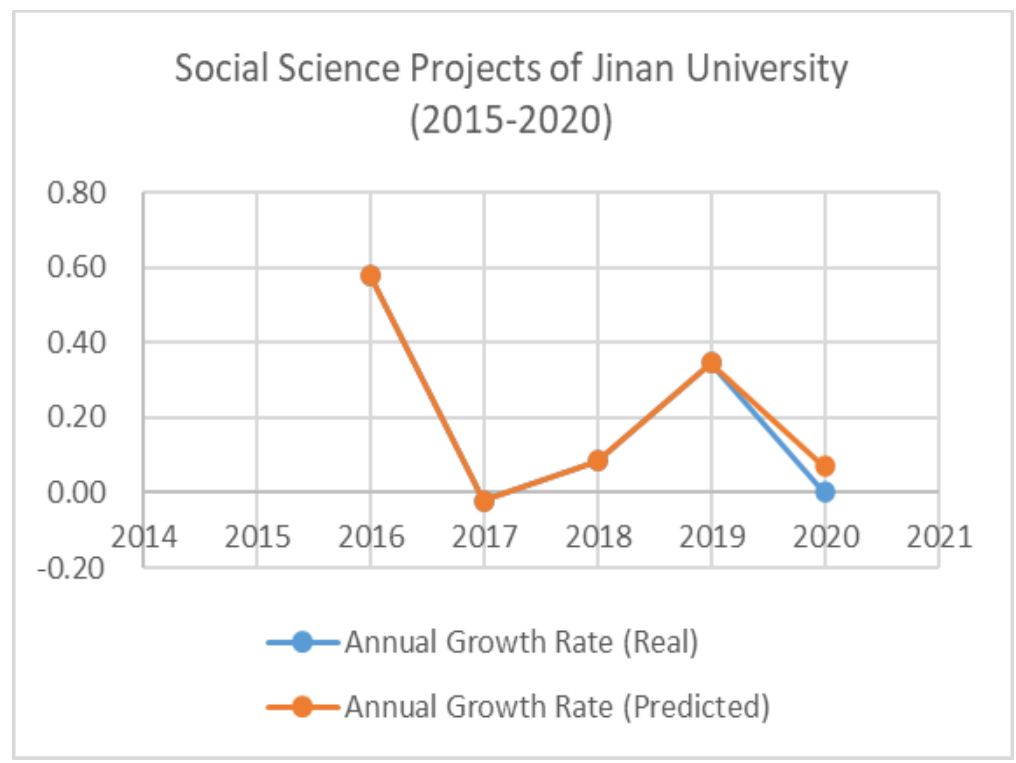

Fig. 2

If we put the real number and predicted number of social science projects into figures for observation, we can see that the difference between them was not so big. This means that the impact of the pandemic on Jinan University's 2020 national social science projects is not significant.

\subsection{Natural Science}

As social science, we input the 2015-2019 national natural science fund projects data of Jinan University into our model GM $(1,1)$. The prediction results showed that if there was no pandemic in 2020 , then Jinan University's 2020 national natural science projects should be 327 items, and the prediction accuracy is 0.993 , so the prediction accuracy is very high.

Table 2. Natural Science Projects of Jinan University (2015-2020)

\begin{tabular}{|c|c|c|c|c|}
\hline \multicolumn{4}{|c|}{ Natural Science Projects of Jinan University (2015-2020) } \\
\hline Year & Projects (real) & Projects (predicted) & \multicolumn{2}{|c|}{ Annual Growth Rate } \\
\hline 2015 & 128 & & Real & Predicted \\
\hline
\end{tabular}


Proceedings of INTCESS 2021 8th International Conference on Education and Education of Social Sciences 18-19 January, 2021

\begin{tabular}{|c|c|r|l|l|}
\hline 2016 & 155 & & 0.21 & \\
\hline 2017 & 242 & & 0.56 & \\
\hline 2018 & 247 & & 0.02 & \\
\hline 2019 & 273 & & 0.11 & \\
\hline 2020 & 293 & 327 & 0.07 & 0.20 \\
\hline $\begin{array}{c}\text { Average Annual } \\
\text { Growth Rate }\end{array}$ & & & 0.19 & 0.22 \\
\hline
\end{tabular}

It can be seen from the table above that the real number of the national natural science projects of Jinan University in 2020 was 293 items, which is 34 less than the predicted result of 327 items with a decrease of $11.6 \%$. According to the forecasting result, the annual growth rate in 2020 should be $20 \%$, but the real situation was $7 \%$, and the annual growth rate has dropped by $13 \%$. The real and predicted average annual growth rates from 2015 to 2020 are $19 \%$ and $22 \%$, respectively.

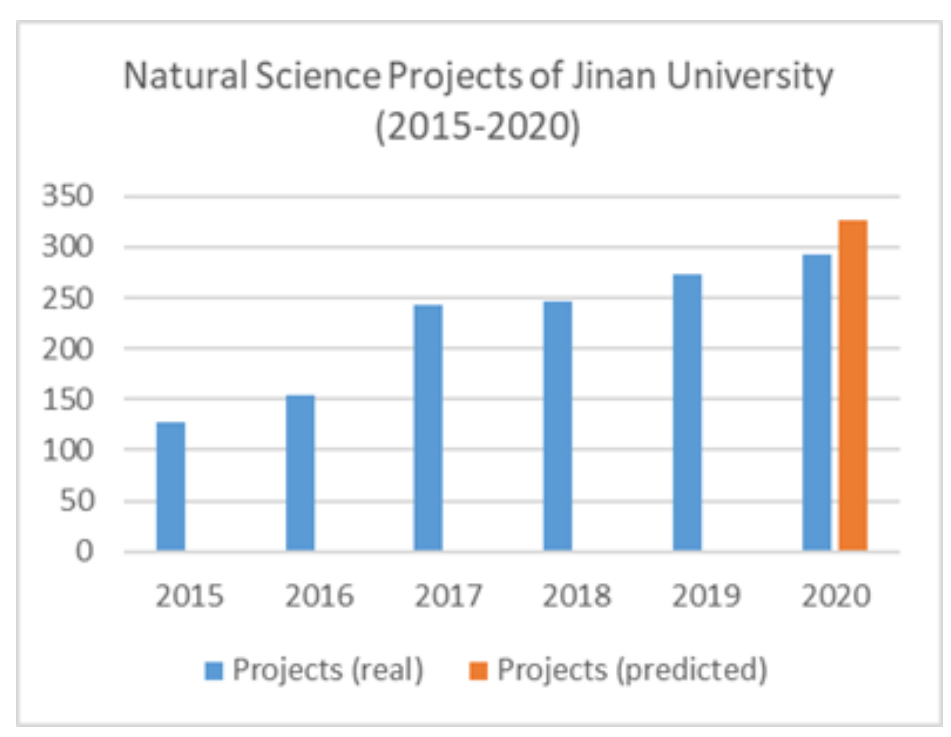

Fig. 3

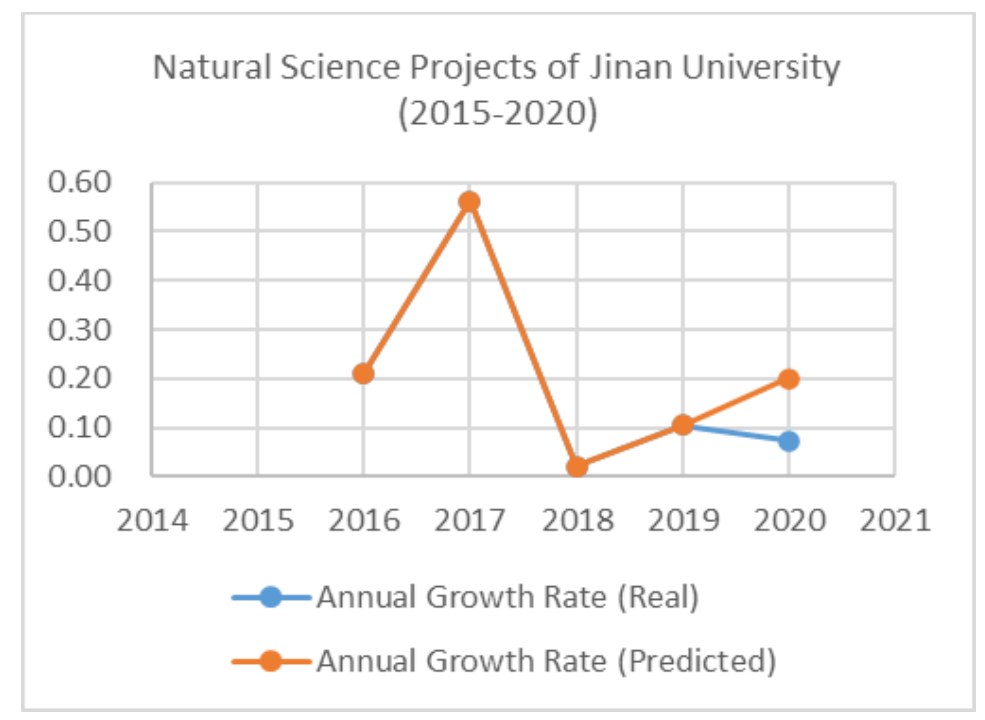

Fig. 4 
If we put the real number and predicted number of the natural science projects of Jinan University into one figure, we can tell that the difference between them was quite big, which was different from the situation of the social science. This shows that the pandemic might have a relatively huge impact on the development of the national natural science projects of Jinan University in 2020 than that of the national social science projects. This coincides with the saying we made above that the advancement of natural science often requires the use of professional equipment for data collection, while social sciences often do not require a large amount of data.

\section{MEASURES}

There are several reasons why the COVID-19 pandemic has such a significant impact on the scientific research of Chinese universities:

1. After the university is closed, researchers cannot use professional equipment to conduct experiments and tests, so they cannot collect important experimental data to complete their research;

2. The delay or cancellation of academic conferences prevents researchers from conducting academic exchanges and hinders the dissemination of the frontier science achievements around the world;

3. Graduate students are required to study at home, and researchers lack sufficient labor to help them complete their daily scientific research work;

4. The establishment and approval of scientific research projects cannot be processed in time, and the administrative management efficiency becomes low due to home-office;

5. Because of the pandemic, many universities have redistributed their funds and cut scientific research expenditures to some extent, which could slow down the scientific research. Besides, this could discourage researchers since their work are attached less importance.

Regarding these reasons, we can set corresponding rules or take some effective measures to reduce the effect of the pandemic on research of universities. The measures can be classified into two levels according to their implementation subjects. The first level is from the perspective of governments. It is governments who could push forward the reform of management of science research in Chinese universities. According to the document issued by the Ministry of Education of China in 2018, universities need to follow the principle of streamlining administration to delegate more powers to lowerlevel administration departments. Universities are required to remove the mechanism barriers of their scientific and technological innovation. Also, they should pay more attention to formulating and perfecting the management principles of scientific research funding, horizontal commission funding, scientific research needed equipment procurement, annual salary system, achievement transformation and scientific research integrity, etc. These measures have been implemented primarily across the country before the pandemic, but after the pandemic broke out, the requirements for scientific research management have become more severe.

The Ministry of Education also required universities to accelerate the construction of digitalization of management, establishing a management and service system covering the whole process of scientific research activities by the end of December 2019. Simplifying reports and procedures, exploring the establishment of one-stop service halls online to implement easiest services can realize the optimization of administration as soon as possible, and establish an innovative, collaborative and efficient scientific research management system. The intensification of the pandemic in $\mathbf{2 0 2 0}$ has prompted universities to make full use of the online office system to reduce documents printed, contacts between different people.

The government must take the initiative to correct the distortion of the evaluation mechanism of scientific research achievements in universities. The reason that causes these phenomena such as heating, preemptive publication of paper, and preemption of scientific research data in the prevention and control of the COVID-19 pandemic is that the mechanism, orientation, and indicators of evaluation of scientific research achievements in universities are not reasonable (Wang, Zhou, Lin, 2020). Therefore, the government should emphasize high-quality evaluation, encouraging researchers and scholars to publish high-quality, high-level paper, increasing the evaluation weight of high-quality results in the whole system, and weakening the negative impact of quantitative indicators on scientific research evaluation.

The second level is from the perspective of universities. Under the premise of ensuring the prevention work in universities, students and staff will be allowed to go back to campus in batches, and an information system will be established to provide convenience for management and response to crises. 
Moreover, various online measures will be taken to improve the real-time monitoring of researchers' health, such as health reporting applications, or health QR code and other information methods, so that we can know the health status, travelling history, and family status of researchers to detect any abnormal condition and resolve it in early time (Liu, Deng, 2020). Through these measures, the campus will gradually recover to the normal situation and continue conducting scientific research. In this way, researchers can make full use of the database and experimental equipment of universities again as soon as possible. If the project members cannot return to school in time, then a new online platform must be built for the cooperation of project members including students.

Universities across the country need to collaboratively create an information sharing platform to comprehensively share their important experimental data and materials. Building a dynamic information platform for scientific research with the help of information technology can realize the effective integration of scientific research resources and provide researchers with efficient information consulting services (Lu, Pan, Yang, 2019). In the management of scientific research in universities, different administration departments should create favorable conditions to promote exchanges and cooperation between different majors, making full use of the different characteristics and advantages of each participants and carrying out interdisciplinary cooperation on major scientific research issues (Li, Liu, 2014). At the same time, different functional departments on the campus, such as the financial management department and the scientific research management department, should also work together to streamline administrative approval process.

\section{CONCLUSIONS}

This paper analyzed the research projects data of Jinan University from 2015 to 2019 with the Gray Model to predict the projects number of 2020 , and compared the predicted results with the real numbers. We found out that the COVID-19 pandemic has affected the scientific research work of Jinan University in several respects significantly. Among them, the influence of natural science research is the most obvious one. In view of this, it is necessary for universities to take specific measures against the pandemic to reduce its negative impact. The implementation of effective measures can be classified into different parts based on different implementation subjects: from the perspective of the government, it should actively promote the reform of scientific research management systems, including delegating power to universities, informatization construction, and correction of scientific research evaluation systems; from the perspective of universities, it is necessary to keep the stable level of prevention and control of the pandemic, and monitor the safety status of researchers, promote the sharing of scientific research information across the country, upgrade the cooperation between different departments in universities, continue the improvement of online platforms. These measures can effectively help the university with the recovery and development of scientific research.

\section{REFERENCE LIST}

Chen, G., Wu, Y. J., Zhang, C. and Jiang, Y. H. (2020). Analysis of Hainan province marine economic development trends. Ocean Development and Management.

Dou, R. T. and Xie, Q. (2020). The scale of China's offshore wind power development based on grey prediction model and trend research, vol.10.

Li, B. D. (2020). The epidemic and the changing world. Boao Forum for Asia.

Li, S. J. and Liu, Y. F. (2014). The construction of scientific research management process in Chinese universities. Management Exploration, vol. 10.

Liu, C. and Deng, H. (2020). Experience and enlightenment of colleges and universities dealing with public crisis. Public Relation World.

Lu, H. Y., Pan, Z. D. and Yang, R. A. (2019). Current situation and development trend of scientific research management research in Chinese universities. Chinese University Science \& Technology.

Marinoni, G., Land, H. and Jensen, T. (2020). The impact of COVID-19 on higher education around the world. International Association of Universities.

Sui, L. J., Sun, Y. Z., Lai, Y. F. and Qiu, T. (2020). Chemical milling thickness prediction based on grey 
Markov process. Measurement and Control Technology, vol.39.

Wang, C. F., Zuo, D. M. and Hong, G. L. (2011). Application of grey system theory in identification of dominant species of infectious diseases and pandemic prediction. Anhui Preserved, vol.17.

Wang, L., Zhou, H. F. and Lin, C. H. (2020). Reflections and suggestions on scientific research management in Chinese universities under the background of the COVID-19 epidemic. Beijing Education, vol. 05.

Wu, F. Y. (2020). Discussion on the application of Gray system in building settlement prediction. Geomatic \& Spatial Information Technology, vol.43.

Zhang, X. F. (2020). The multiple impacts of COVID-19 prevention and control on higher education in China. Beijing Education.

Zhao, C. (2020). Different regional distribution of technological talents and their effects. Science and Technology Review, vol. 38.

Zhu, B. and Gu, W. (2020). Research on the impact of the COVID-19 on Chinese GDP. Economic Research, vol. 10 . 